\title{
BIOEFFICACY OF DIFFERENT INSECTICIDES AGAINST BLISTER BEETLE Mylabris phalerata (Pallas) ON PIGEONPEA
}

\author{
A.K. Singh ${ }^{1^{*}}$ \\ ${ }^{1}$ AICRP (Honey Bees \& Pollinators), NU, SASRD, Nagaland, India
}

\begin{abstract}
The experiment was accomplished to evaluate the bioefficacy of different insecticides against Mylabris phalerata (Pallas) on pigeonpea. The experiment consisted of seven treatments viz., bifenthrin $62 \mathrm{~g}$ a.i. $\mathrm{ha}^{-1}$, lambda-cyhalothrin $24 \mathrm{~g}$ a.i. ha $^{-1}$ (encapsulated with polymers; Matadore), chlorpyriphos $310 \mathrm{~g}$ a.i. ha ${ }^{-1}+$ cypermethrin $31 \mathrm{~g}$ a.i. ha ${ }^{-1}$, cypermethrin $62 \mathrm{~g}$ a.i. ha $^{-1}$, neem oil $1500 \mathrm{ppm}$, permethrin $154 \mathrm{~g}$ a.i. ha 1, chloropyriphos $173 \mathrm{~g}$ a.i. ha ${ }^{-1}$ compared with untreated (control). The sixth day after each spray, minimum population abundance of $M$. phalerata and maximum percent efficacy in reducing their population was obtained from bifenthrin which was at par with lambda-cyhalothrin, cypermethrin, chlorpyriphos+ cypermethrin and permethrin and all these were significantly effective over chloropyriphos, neem oil and control plots. On the tenth day after each spray, minimum population abundance and highest per cent efficacy were obtained from bifenthrin which was at par with lambda-cyhalothrin and both these treatments were significantly superior over rest of the treatments. The maximum productivity was observed with bifenthrin, while highest net return per rupee investment was obtained from lambda-cyhalothrin treatment. The results explicitly show that out of all treatments, Lambda-cyhalothrin was effective and imposing lucrative against $M$. phalerata and thereby minimized the yield loss. Three sprays of lambda-cyhalothrin and bifenthrin with an interchange at ten days interval will be effectual and lucrative against $M$. phalerata in short duration pigeonpea crop.
\end{abstract}

Keywords: Blister beetle, Mylabris phalerata, pigeonpea, bioefficacy, insecticides

\section{INTRODUCTION}

Pigeonpea (Cajanus cajan L.) is one of the most important pulse crop cultivated in more than 25 countries of the world on 6.67 million ha with 4.86 million ton of production, whereas in Asia, it was grown on 5.69 million ha and producing

*Corresponding author email: dr.akhileshento@ rediffmail.com

Received: 04.01.2016 
3.88 million ton in 2014 (FAO, 2016). The economic loss due to biotic stress factors has been estimated to be US\$ 8.48 billion (Sarika et al., 2013) in the world. The big difference of pigeonpea productivity shows great promises to enhance the crop productivity by management of biotic constraints. Among biotic constraints for productivity in subsistence crop protection pattern, Mylabris phalerata is one of the most detrimental insect pests. In pigeonpea, owing to the introduction of short duration, photo-insensitive and determinate varieties with compact floral clusters, damage by blister beetles tends to be manifold.

Blister beetle is a voracious flower feeder and thereby, directly affects the grain yield through flower damage. Pigeonpea is the most preferred host for blister beetle at reproductive stage (Mann and Dhooria, 1993; Balikai, 2000; Durairaj, 2000; Dhakla et al., 2010; Dasbak et al., 2012). Its species damaged pigeonpea flowers with the maximum beetle density 19.4 plant $^{-1}$ (Durairaj and Ganapathy, 1996). It has significant pest characteristics viz., polyphagous, voracious feeder, high mobility, robustness, high fecundity and the immature stage buried subterranean can safely surpass transitional life cycle in soil. Adult blister beetles are migratory in nature and therefore, all the insecticides may not effectively control those (Blodgett et al., 2010). As per their biology and behaviour, its management is hard headed. Several management options were given to suppress blister beetles population but none of them could overcome the menace (McBride, 2012). Unfortunately, various insecticides do not effectively suppress their population due to its behavioural ability. However, chemical management strategy shows great promises with various potentials viz., practical management, cost effectiveness, farmers' reliance and quick response to overcome their damage. Hence, the present investigation was envisaged to unequivocally substantiate and determine the bio-efficacy of contact, knockdown and deterrent features based insecticides against $M$. phalerata on pigeonpea.

\section{MATERIALS AND METHODS}

The experimental materials consisted of pigeonpea, $M$. phalerata and different insecticides. The experiment was accomplished under field conditions at Agronomy Research Farm of School of Agricultural Sciences and Rural Development, Nagaland University, Medziphema, during 2014 and 2015 on the early variety of pigeonpea, UPAS 120. The pigeonpea crop was raised as per recommended package of practices for north east India. The experiment was designed in randomized block design with 8 treatments including control (untreated) and replicated thrice.

The treatments were assigned bifenthrin $62 \mathrm{~g}$ a.i. $\mathrm{ha}^{-1}$, lambda-cyhalothrin (encapsulated with polymers; Matadore) $24 \mathrm{~g}$ a.i. ha ${ }^{-1}$, cypermethrin $31 \mathrm{~g}$ a.i. $\mathrm{ha}^{-1}+$ chlorpyriphos $310 \mathrm{~g}$ a.i. ha ${ }^{-1}$, cypermethrin $62 \mathrm{~g}$ a.i. ha $^{-1}$, neem oil $1500 \mathrm{ppm}$ (1235 $\mathrm{ml} \mathrm{ha}^{-1}$ ), permethrin $154 \mathrm{~g}$ a.i. ha ${ }^{-1}$, chloropyriphos $173 \mathrm{~g}$ a.i. $\mathrm{ha}^{-1}$ and untreated (control) which were evaluated for their efficacy against blister beetle on pigeonpea. Insecticides were applied thrice during infestation (blooming stage) of crop and 
sprays were applied as per requirement basis with high pressure knapsack power sprayer.

The population abundance of blister beetle and grain yield of pigeonpea data were collected from the replicated plots of each treatment. Ten plants were selected randomly from each plot, and population of adults was counted from 0600 to $1000 \mathrm{~h}$. The blister beetle incidence was recorded one day before spray as pre-treatment and on the sixth day and tenth day after sprays as post-treatment. The percent reduction of population over untreated which is expressed as percent efficacy of insecticide was calculated by Henderson and Tilton's formula as given below,

Per cent efficacy $=\left[1-\frac{\mathrm{Ta}}{\mathrm{Tb}} \times \frac{\mathrm{Cb}}{\mathrm{Ca}}\right] \times 100$

Where,

$\mathrm{T}_{\mathrm{a}}$ - Population of the treated plot after spray

$\mathrm{T}_{\mathrm{b}}$ - Population of the treated plot before spray

$\mathrm{C}_{\mathrm{a}}$ - Population of the control plot after spray

$\mathrm{C}_{\mathrm{b}}$ - Population of the control plot before spray

The efficacy data were transformed in square root transformation as per transformation rule one (Gomez and Gomez, 1983). The productivity of seed yield was recorded plot $^{-1}$ and the obtained grain yields were converted in $\mathrm{kg} \mathrm{ha}^{-1}$. The avoidable yield loss due to application of different treatments was derived by deducting the yield of untreated from respective treatments. The incremental benefit cost ratio was calculated as per increase in the yield over untreated with experiment year MSP of pigeonpea. The data of each character were subjected to statistical test by applying analysis of variance technique (Gomez and Gomez, 1983).

\section{RESULTS AND DISCUSSION}

\section{Blister beetle population abundance and bioefficacy of insecticides}

The recorded population abundance of $M$. phalerata and per cent efficacy of different insecticides have been depicted in table 1 and 2. Before the first spray, mean population of $M$. phalerata varied from 1.73 to 1.93 plant $^{-1}$ and 1.80 to 2.03 plant $^{-1}$ during 2014 and 2015 respectively from various assigned treatments and statistically identical with each other. On the sixth day after the first spray, the lowest population plant $^{-1}(0.47)$ and highest efficacy $(73.93 \%)$ were recorded with bifenthrin followed by lambda-cyhalothrin, cypermethrin, chlorpyriphos+ cypermethrin and permethrin which were at par to each other and significantly effective in reducing the population over chloropyriphos, neem oil and control (untreated) during 2014 and the same trend was observed in 2015 . On the tenth day after first spray, the lowest population plant ${ }^{-1}$ (1.40) and highest efficacy $(36.36 \%)$ were recorded with bifenthrin followed by lambda-cyhalothrin which were at par to each other and significantly superior in 
efficacy and reducing the population over rest of the treatments including untreated plots. By the tenth day after first spray, the efficacy of chlorpyriphos+ cypermethrin, cypermethrin, neem oil, permethrin and chloropyriphos treatments were statistically at par with control (untreated) during 2014 in reducing the population and efficacy and the similar trend was observed in 2015.

Before the second spray, the population plant ${ }^{-1}$ varied from 2.23 to 2.60 and 2.03 to 2.33 during 2014 and 2015 respectively, which were statistically at par with each other. On the sixth day after the second spray, the lowest population plant ${ }^{-1}$ (0.43) and highest efficacy $(78.42 \%)$ were recorded with bifenthrin followed by lambda-cyhalothrin, cypermethrin, permethrin and chlorpyriphos+ cypermethrin which were statistically at par to each other and significantly superior in efficacy and in reducing the population over chloropyriphos, neem oil and control (untreated) during 2014 and the same trend was observed in 2015. Again, on the tenth day after second spray, the lowest population plant ${ }^{-1}(1.27)$ and highest efficacy $(35.72 \%)$ was recorded with bifenthrin followed by lambda-cyhalothrin which were at par to each other and significantly superior in efficacy and reducing the population over rest of the treatments including untreated plots. On the tenth day after second spray, the efficacy of chlorpyriphos+ cypermethrin, cypermethrin, neem oil, permethrin and chloropyriphos treatments were statistically at par with control (untreated) in efficacy and reducing the population during 2014 and the similar trend was observed in 2015.

Before the third spray, population plant ${ }^{-1}$ varied from 1.73 to 2.43 and 2.13 to 2.33 during 2014 and 2015 respectively, which were statistically at par with each other. On the sixth day after the third spray, the lowest population plant $^{-1}(0.37)$ and highest efficacy $(78.44 \%)$ were recorded with bifenthrin followed by lambdacyhalothrin, chlorpyriphos+ cypermethrin, cypermethrin and permethrin which were statistically at par to each other and significantly superior in efficacy and reducing the population over chloropyriphos, neem oil and control (untreated) during 2014 and the same trend was observed in 2015. Again, on tenth day after third spray, the lowest population plant $^{-1}(0.90)$ and highest efficacy $(22.17 \%)$ were recorded with bifenthrin followed by lambda-cyhalothrin which were at par to each other and significantly superior in reducing the population and efficacy over rest of the treatments including untreated plots. By the tenth day after third spray, the efficacy of chlorpyriphos+ cypermethrin, cypermethrin, neem oil, permethrin and chloropyriphos treatments were statistically at par with control (untreated) in efficacy and reducing the population of $M$. phalerata during 2014 and the similar trend was observed in 2015.

\section{Effects of various treatments on the productivity and incremental benefit cost ratio}

The pigeonpea crop productivity $\left(\mathrm{kg} \mathrm{ha}^{-1}\right)$ of various treatments has been depicted in table 3. The efficacy of all the treatments to reduce the $M$. phalerata population was reflected on the pigeonpea productivity. The data explicitly showed that the highest yield $\left(1402.91 \mathrm{~kg} \mathrm{ha}^{-1}\right)$ was recorded with bifenthrin followed by 
lambda-cyhalothrin, cypermethrin, chlorpyriphos+ cypermethrin and permethrin which were statistically at par to each other and significantly superior over chloropyriphos, neem oil treatments and untreated plots during 2014 and the similar trend was observed in 2015.

The cost of control measures of $M$. phalerata and their effects on productivity was reflected on incremental benefit cost ratio of the various treatments which has been depicted in table 3 . The incremental benefit cost ratios revealed that the bifenthrin, lambda-cyhalothrin, chlorpyriphos+ cypermethrin, cypermethrin and permethrin treatments were lucrative in comparison with untreated plots while chlorpyriphos and neem oil were economically not viable during both experimental years. The highest incremental benefit cost ratio (1:9.45) was obtained from lambdacyhalothrin (matador) followed by bifenthrin (1:8.62), cypermethrin (1:6.87), chlorpyriphos+ cypermethrin (1:6.08), permethrin (1:5.90), chlorpyriphos (1:0.99) and neem oil (1:0.73) during 2014 and an almost similar trend was obtained during 2015. The highest net return per rupee of investment (8.45) was obtained from lambda-cyhalothrin (matador) followed by bifenthrin (7.62), cypermethrin (5.87), chlorpyriphos+ cypermethrin (5.08), permethrin (4.90), chlorpyriphos (-0.01) and neem oil (-0.27) during 2014 and an almost similar trend was obtained during 2015. The incremental benefit cost ratio variation may be due to yield difference and cost of the insecticides, which has been explicated in above results.

These present findings are in confirmation with Ali et al. (2005) reported that the lowest number of insects spotted bollworms was obtained in bifenthrin and lambda-cyhalothrin treated plots, however, cypermethrin was not as effective as the above mentioned insecticides. Pyrethroids; cypermethrin and lambda-cyhalothrin were most effective than the other groups of insecticides against blister beetles (Sharma et al., 2010; Shende et al., 2013). The cypermethrin and chlorpyriphos+ cypermethrin were promising with consistently lower blister beetle population (Pawar et al., 2013). There was significant difference in per cent efficacy on sixth day after sprays of all pyrethroids based pesticides in comparison to chloropyriphos and neem oil. Pyrethroids treatments effectively controlled blister beetles in comparison to neem-Azal (Dikshit et al., 2001).

The significant difference in per cent efficacy on the tenth day after sprays of bifenthrin in comparison to other insecticides might be attributed due to its long persistence. The bifenthrin is more stable than chlorpyriphos (Baskaran et al., 1999). At high dose, residues of bifenthrin persisted up to 15 days in leguminous crop (Mukherjee et al., 2010). The significant difference in per cent efficacy on the tenth day after sprays of lambda-cyhalothrin (matador) in comparison to other pesticides might be attributed due to lambda-cyhalothrin encapsulated with polymers. The encapsulation process provides the long-lasting characteristic due to its ability curtail to its degradation. Micro-encapsulation technology is reduced evaporative losses and 
Table 1. Bioefficacy of different insecticides against M. phalerata on pigeonpea during 2014

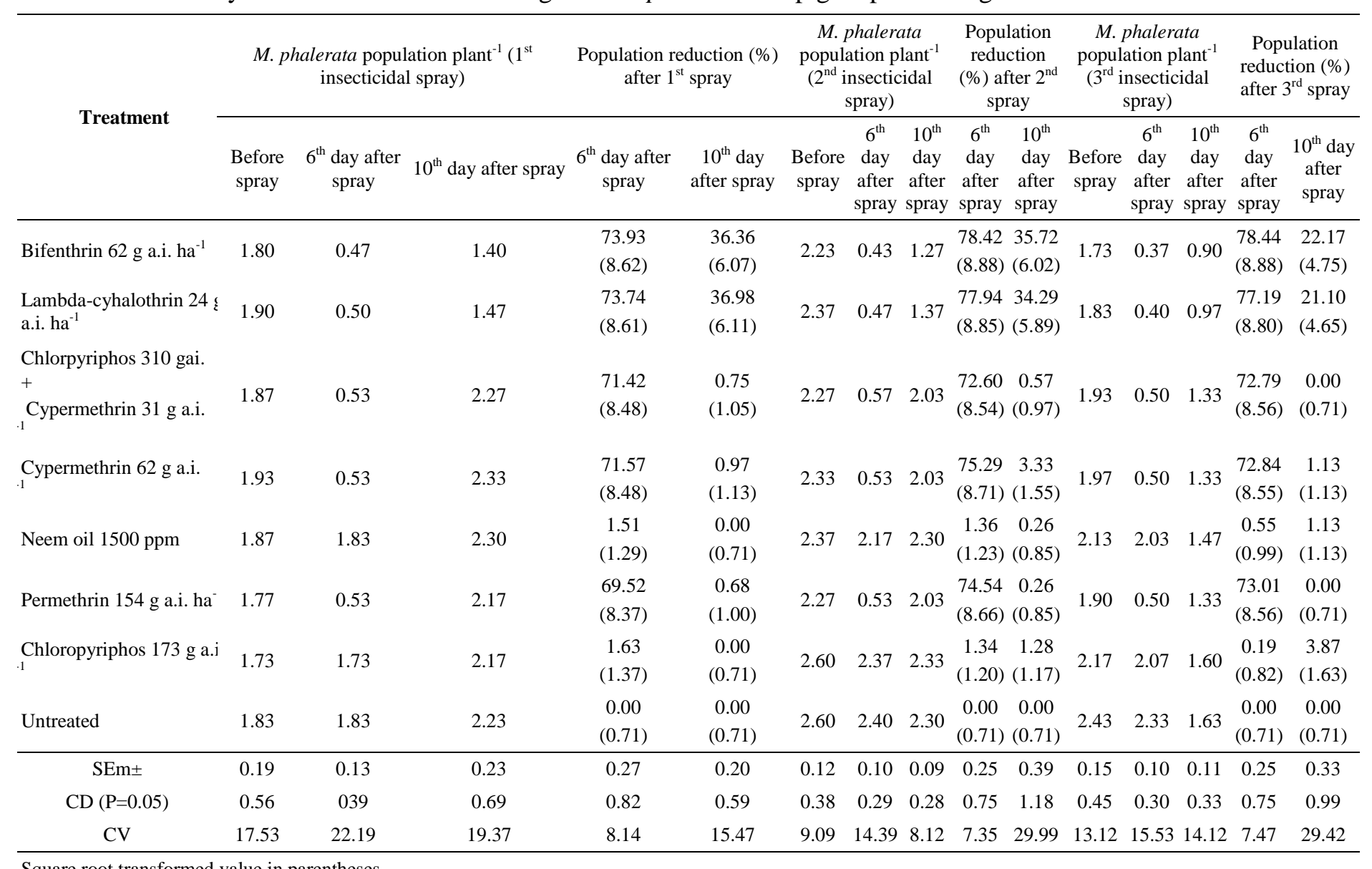

Square root transformed value in parentheses 
Table 2. Bioefficacy of different insecticides against $M$. phalerata on pigeonpea during 2015

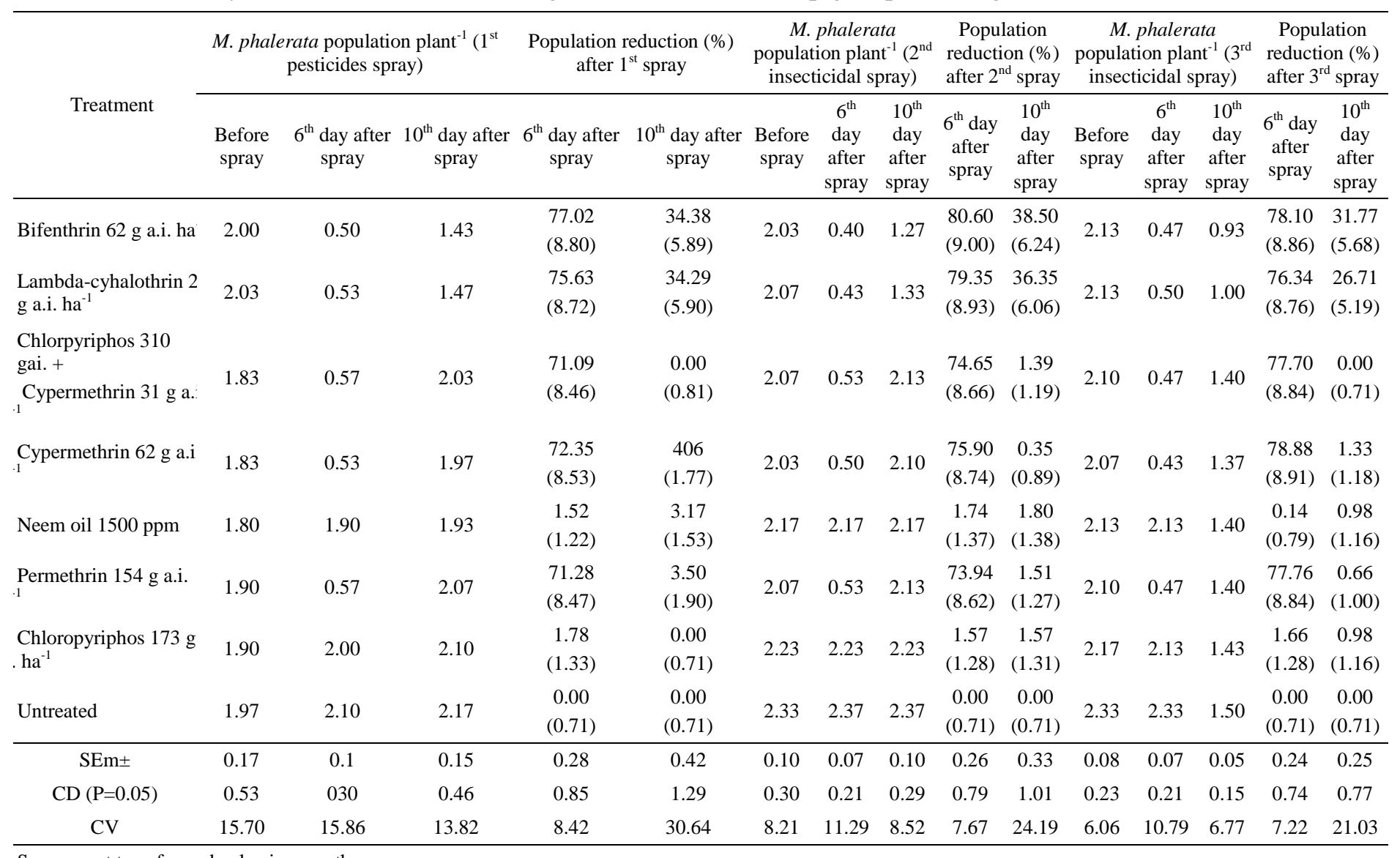

Square root transformed value in parentheses 
Table 3. Effects of various treatments against $M$. phalerata on the productivity of pigeonpea and incremental benefit cost ratio

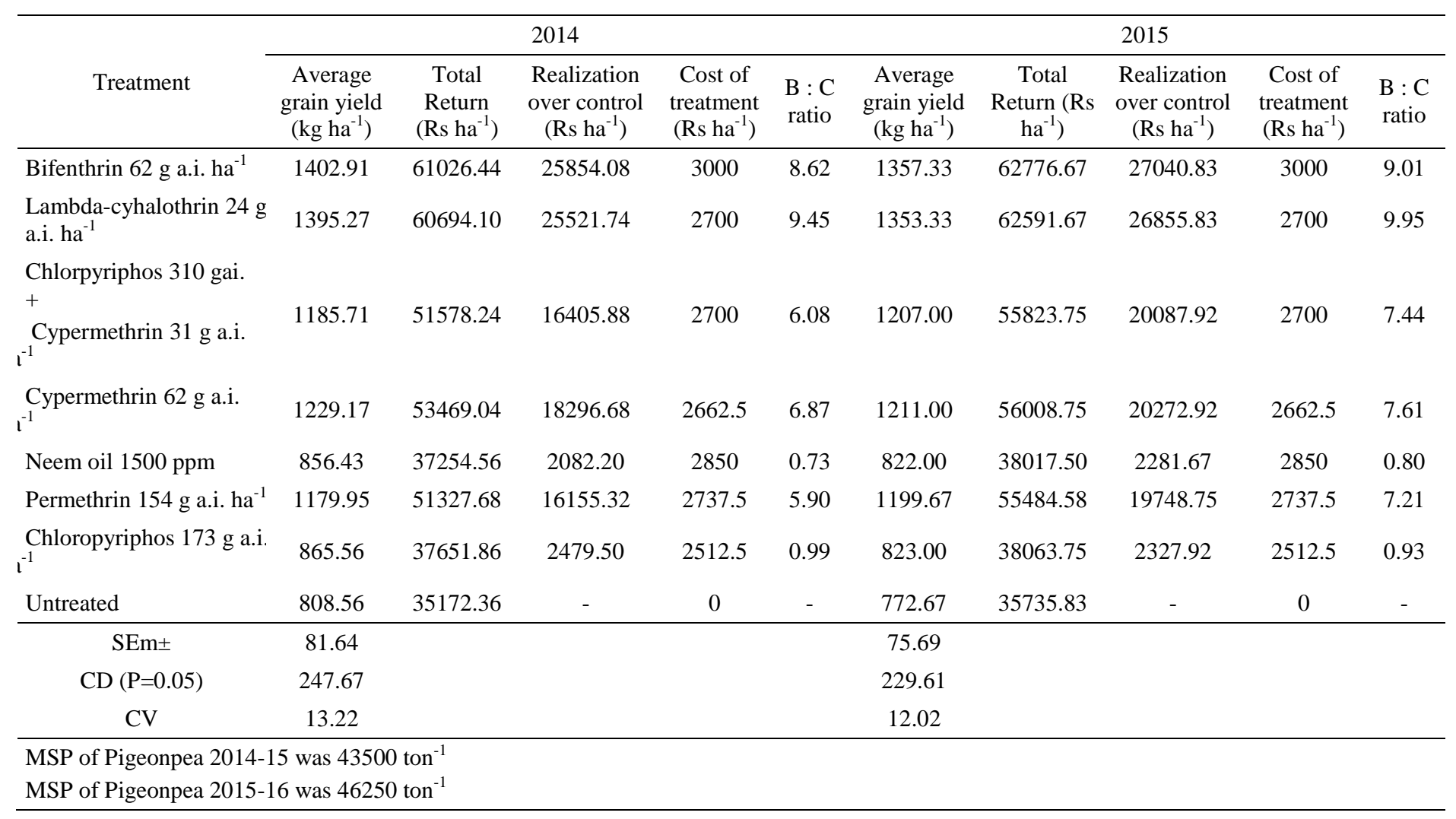


therefore, reduces environmental degradation (Shirley et al., 2001; Knowles, 2008). The polymer wall retains the lambda cyhalothrin for extended periods on inert or chemically active surfaces, reducing losses from adsorption and chemical reaction (Wege et al., 1999).

The maximum yield was observed in bifenthrin and lambda-cyhalothrin and minimum in control plots. The yield up to some extent, might be varied due to damage of reproductive parts as flowers by blister beetle and similarly, (Kemal and Kocak, 2008) reported that blister beetle reduces crop yield through direct feeding of its flowers. The highest grain yield of pigeonpea was recorded from bifenthrin, which is significantly identical with lambda-cyhalothrin, although cost of bifenthrin treatment was much higher than the lambda-cyhalothrin. Therefore, the incremental benefit cost ratio analysis revealed superiority of lambda-cyhalothrin and impose lucrative net return per rupee of investment followed by bifenthrin, cypermethrin, permethrin and chlorpyriphos+ cypermethrin. This result was in conformity with the findings of (Singh et al., 2009; Pawar et al., 2013).

\section{CONCLUSION}

In conclusion, bifenthrin, lambda-cyhalothrin (encapsulated with polymers), cypermethrin, chlorpyriphos+ cypermethrin and permethrin proved effectual to suppress the $M$. phalerata population up to five days. However, bifenthrin and lambda-cyhalothrin were superior and most effectual to suppress the population with high efficacy up to ten days. The lambda-cyhalothrin was found highest incremental benefit cost ratio. The results inferred that the both bifenthrin and lambda-cyhalothrin confers excellent protection up to ten days, but, blooming period of pigeonpea variety UPAS 120 is about 30 days in normal weather conditions. Hence, three sprays of lambda-cyhalothrin and bifenthrin with an interchange at ten days interval will be effectual and lucrative against $M$. phalerata in short duration pigeonpea crop.

\section{ACKNOWLEDGMENT}

This research was meticulously accomplished under All India Coordinated Research Project on (Honey Bees \& Pollinators) funded by Indian Council of Agriculture Research and conducted in the School of Agriculture Sciences \& Rural Development, Nagaland University, Medziphema. The author expresses heartiest gratitude to the funding agency and the host institution. I would like to thanks to Mr. Ngukho and Mr. Akum for valuable their support. 


\section{REFERENCES}

Ali, M.A., Rafiq-u-Rehman, Tatla, Y.H. and Ali, Z. 2005. Efficacy of different insecticides against spotted bollworms (Earias Spp.) at Karor, Layyah. Pakistan Entomologist, 27(1): $1-4$

Balikai, R.A. 2000. Incidence of blister beetle, Mylabris pustulata (Thunberg) on different host plants. Insect Environment, 6 (1): 12

Baskaran. S., Kookana, R.S. and Naidu, R. 1999. Degradation of bifenthrin, chlorpyrifos and imidacloprid in soil and bedding materials at termiticidal application rates. Pesticide Science, 55: 1222-1228

Blodgett, S.L., Denke, P.M. and Knerr, V. 2010. Blister beetles of Montana. Montana State University Extension Service MT200209 AG, 100-210SA. Pp1-4

Dasbak, M.A., Echezona, B.C. and Asiegbu, J.E. 2012. Field insect pests and crop damage assessment of pigeonpea (Cajanus cajan [L.] Huth) grown under ratoon and in mixture with maize. Chilean journal of agricultural research, 72(1): 45- 52

Dhakla, K., Yadav, G.S. and Rohilla, H.R. 2010. Incidence and flower damage of pigeonpea genotypes by blister beetle, Mylabris Pustulata. Thunberg, 23 (3): 348-350

Dikshit, A.K., Lal, O.P. and Kumar, R. 2001. Persistence and bioefficacy of insecticides in okra and sponge gourd. Journal of the Entomological Research, 25(2): 131-136

Durairaj, C. 2000. A note on the host preference by two species of blister beetle in pulse crops. Madras Agricultural Journal, 87 (4/6): 355-356

Durairaj, C. and Ganathy, N. 1996. Identification of blister beetle complex on pigeonpea in Tamil Nadu, India. International Chickpea and Pigeonpea Newsletter, 3: 96

FAO, 2016. FAO Agricultural Statistical Database. Available at http://faostat.org/beta/en/\#data. Accessed on 20 November 2016

Gomez, K.A. and Gomez, A.A. 1983. Statistical procedures for agricultural research $\left(2^{\text {nd }}\right.$ edition). A Wiley-interscience publication, New York, USA. 680p

Kemal, M. and Kocak, A.O. 2008. Occurrence of two Epicauta species in Asia with some notes (Coleoptera, Meloidae). Cesa News, 34: 1-4

Knowles, A. 2008. Recent developments of safer formulations of agrochemicals. The Environmentalist, 28(1): 35-44

Mann, G.S. and Dhooria, M.S. 1993. Feeding and mating behaviour of blister beetle on pigeonpea. International Pigeonpea Newsletter, 17: 40-42

McBride, D.K. 2012. Blister Beetles. NDSU, Extension Service, www.ag.ndsu.edu, E-1002

Mukherjee, I., Singh, R. and Govil, J.N. 2010. Risk assessment of a synthetic pyrethroid, bifenthrin on pulses. Bulletin of Environmental Contamination and Toxicology, 84: 294-300

Pawar, K.S., Shende, S., Wadaskar, R.M. and Thakare, A.Y. 2013. Studies on insecticide efficacy and application schedule for management of blister beetles on green gram. Journal of Food Legumes, 26: 63-69 
Sarika, A.V., Iquebal, M.A., Rai, A. and Kumar, D. 2013. PIPEMicroDB: microsatellite database and primer generation tool for pigeonpea genome. Database, 2013 Article ID bas054, doi:10.1093/database/bas054. (http://database.oxfordjournals.org)

Sharma, O.P., Gopali, J.B., Yelshetty, S., Bambawale, O.M., Garg, D.K. and Bhosle, B.B. 2010. Pests of pigeonpea and their management. NCIPM, LBS Building, IARI Campus, New Delhi, India. pp. 97

Shende, S., Thakare, A.Y. and Wadaskar, R.M. 2013. Dose mortality responses of blister beetles against some insecticides. The Bioscan, 8(3): 1061-1064

Shirley, I.M., Scher, H.B., Perrin, R.M., Wege, P.J., Rodson, M., Chen, J.L. and Rehmke, A.W. 2001. Delivery of biological performance via micro-encapsulation formulation chemistry. Pest Management Science, 57(2): 129132

Singh, A.K., Srivastava, C.P. and Joshi, N. 2009. Evaluation of integrated pest management modules against gram pod borer in chickpea (Cicer arietinum). Indian Journal of Agricultural Sciences, 79(1): 49-52

Wege, P.J., Hoppe, M.A., Bywater, A.F., Weeks, S.D. and Gallo, T.S. 1999. A microencapsulated formulation of lambda-cyhalothrin. In Proceedings of the $3^{\text {rd }}$ international conference on urban pests, Pp. 19-22 